\title{
An Empirical Vision for Organizational Renewal: Utilizing Self-Reflection and Self-Awareness to Prompt Deep Transformation
}

\author{
Jillian Gilbert $^{1}$ \\ ${ }^{1}$ School of Business and Management, Azusa Pacific University, Azusa, California, USA \\ Correspondence: Jillian Gilbert, School of Business and Management, Azusa Pacific University, 901 E. Alosta Ave., \\ Azusa, Ca., USA. Tel: 1-626-815-6000 ext. 3787.
}

Received: March 17, 2016

Accepted: April 1, 2016

Online Published: April 22, 2016

doi:10.5430/ijba.v7n3p1

URL: http://dx.doi.org/10.5430/ijba.v7n3p1

\begin{abstract}
Though it would not be disputed that individual contributors within the organization are pivotal to organizational innovation and change, there seems to be a disconnect between the organization's design as it pertains to systems, structures and policies and those in leadership who determine the realities, norms, and behaviors for how innovation is to take place. Often, the implicit leadership influence in regard to this is unspoken and separate from the established organizational culture. For this reason, before an organization has this ability to renew on a product and innovation level, deeper renewal may be required. This renewal process utilizes principles of self-reflection and self-awareness to gain greater understanding of how the many dimensions of the organization work together. This method of organizational renewal can be extremely beneficial regardless of the current state of the organization. The key is to consider renewal as a form of strengthening the very core for greater sustainability and future readiness. This article provides an empirical framework to illuminate ways in which an organization can engage in the renewal process. The process involves discussing the importance of renewal at all levels of the organization, providing the foundational concepts of self-reflection and self-awareness in the context of renewal, highlighting the various aspects of the organization requiring renewal, and bringing it all together into a cohesive framework
\end{abstract}

Keywords: organizational renewal, leadership, self-reflection, self-awareness

\section{Introduction}

Organizations are a complex and organic blend of people and systems (Wren and Bedeian, 2009). This complexity derives from the convergence of organizational systems and the values and culture of people within those systems. Where the two converge becomes a strategic point that either generates or prohibits organizational growth. The history of management thought demonstrates the ever-changing atmosphere and focus of the organization and the importance of design not just in its formative years, but also throughout its life span. Additionally, throughout history, there have been organizational beginnings and endings both philosophically and literally. The twenty first century is no different. As there continues to be an accelerated rate of change (Wind, 2006), the tides are shifting once again and what once were clear and delineated methods for organizational effectiveness is beginning to blur (Wind, 2006). Just in the last few years alone the impact of declining economies worldwide, natural disasters, and costly wars have generated the need for new emerging thoughts on what will aid the organization in remaining sustainable in the midst of chaos. Even more, there is a need to seek greater awareness of current organizational readiness for what lies beyond the horizon (Cornish, 2004). Unfortunately, many organizations discover that they have missed key opportunities to seek this greater awareness. There could be various reasons for this, one of which is the absence of continual renewal. The renewal process is what enables organizations to remain aware of the present climate both internally and externally (Maslach \& Leiter, 1997) as well as the opportunity to reflect on key areas of design that drive the organization's ethos.

For those who fail to incorporate organizational renewal as a key practice may discover that the organization is not as resilient and sustainable as originally thought. Some may even be facing finality where the only option that remains is to completely reinvent or experience a slow death (Quinn, 1996). Organizations finding themselves in this challenging situation still have an opportunity to renew and possibly even build in necessary structures and design to bring the organization back to a position of long-term sustainability. In order to accomplish this, the organization should consider utilizing a renewal process that attempts to enlighten the areas of weakness both on a human 
dynamic level and systematic level. This can assist in realigning all aspects of the organization. This renewal process utilizes principles of self-reflection and self-awareness to gain greater understanding of how the many dimensions of the organization work together. This method of organizational renewal can be extremely beneficial regardless of the current state of the organization. The key is to consider renewal as a form of strengthening the very core for greater sustainability and future readiness.

This paper provides an empirical framework to illuminate ways in which an organization can engage in the renewal process. The process involves discussing the importance of renewal at all levels of the organization, providing the foundational concepts of self-reflection and self-awareness in the context of renewal, highlighting the various aspects of the organization requiring renewal, and bringing it all together into a cohesive framework.

\section{Organizational Renewal}

In general, organizational renewal thought centers around the organization's ability to engage in change. This change may vary from consistent maintenance, adapting to trends, or generating various types of innovation (Junelle and Stahle, 2011). For some authors such as Junelle and Stahle (2011), renewal is a three dimensional phenomenon which organizations develop the ability to: 1.) Routinize and operationalize activities and current knowledge; 2 .) Utilize feedback to incrementally develop and grow knowledge for effective process and service; 3.) Provide disruptive knowledge and innovations (Junelle and Stahle, 2011). The basis for this model of renewal, one could argue, is the predominant theme in organizational renewal literature and centers on change principles and growth from a knowledge base perspective. That is, personnel knowledge. In innovation terms, knowledge creation is the cornerstone to effective and collaborative innovation (Vonkrogh, Ichijo, and Nonaka, 2000). Though it would not be disputed that individual contributors within the organization are pivotal to organizational innovation and change, there seems to be a disconnect between the organization's design as it pertains to systems, structures and policies and those in leadership who determine the realities, norms, and behaviors for how innovation is to take place. Often, the implicit leadership influence in regard to this is unspoken and separate from the established organizational culture. For this reason, before an organization has this ability to renew on a product and innovation level, deeper renewal may be required. This type of renewal is highly personalized and relies on self-awareness and self-reflection both at the organizational level and the leadership level.

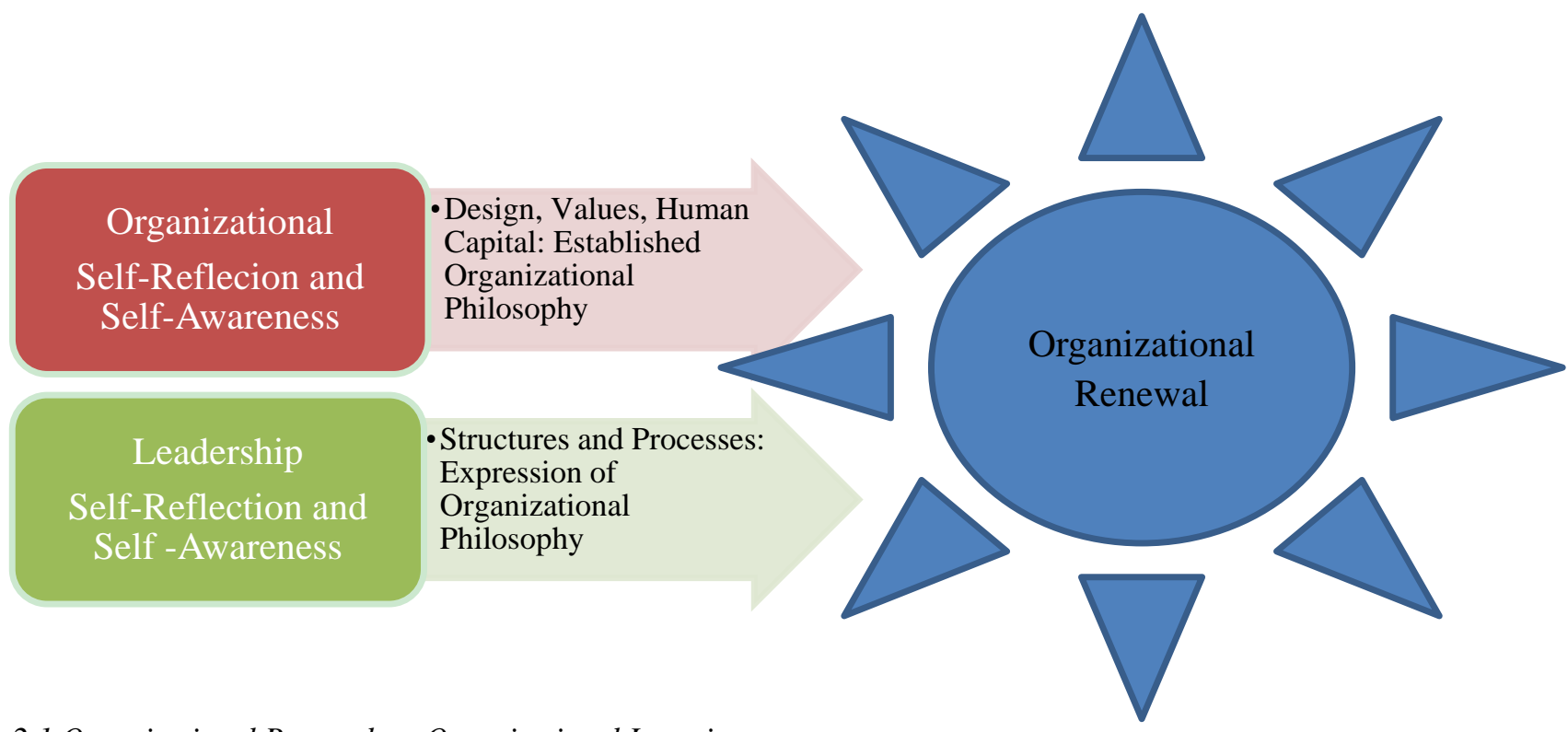

\subsection{Organizational Renewal vs. Organizational Learning}

Pham and Swierczek (2006) articulate organizational learning as a process in which individuals gain knowledge, internalize knowledge, change behaviors to incorporate new knowledge and then brings this new behavior to the collective, prompting change at the organizational level. Knowledge, in this case, is referred to as a competency related process. Additionally, Pham and Swierczek (2006) address organizational learning as a predominately individual phenomenon without a dramatic affect to the larger movement of the organization. Additionally, Crossan and Berdrow (2003) establish through their empirical research that organizational learning is sometimes unplanned and is seen as an emergent process in which there is no intentional or strategic view of the outcomes of desired 
learning. Pokharel and Choi (2015) further distinguish organizational learning from the framework of opportunities for individuals within the organization to experience growth through learning opportunities, dialogue with others, and empowerment all which are extremely valuable to the motivation factors of employees. With this, organizational learning is vital to change and renewal, however, fundamentally it addresses the state of the organization and the individuals within it from a knowledge and effectiveness perspective. In contrast to organizational learning, it can be suggested that for true change to take root as a result of learning, the starting point for sustainable change rests in the deeper more intricate pieces of the organization. In this, the difference between organizational learning and renewal is the starting point by which the change is made. It can be suggested that for true organizational renewal to take root and change the organization it is to be done through a transformative process. This would involve intentionality through viewing learning strategically (Crossan and Berdrow, 2003), addressing the organization's capability to engage in effective renewal (Junelle and Stahle, 2011) as well as, and more importantly, evaluating and exploring the power of character development both individually and corporately.

\subsection{The Importance of Renewal}

Though it is ideal that organizations are continually renewing themselves through self-awareness and self-reflection, there are various reasons why this does not actually occur. Many of these reasons are as a result of individual behaviors and reactions. First, many leaders do no practice personal wellness and neglect their own growth and development. In doing so, the result is usually leadership burnout (O'Neil, 1993). When this occurs, leaders neglect themselves and often lose insight into their own effectiveness in the context of organizational decisions (Grant, et al., 2007). Second, sometimes the fast-paced environment of the larger organization generates a behavior that neglects the overall corporate health, which creates a culture that does not operate with a cohesive awareness (Maslach \& Leiter, 1997) thus affecting innovation. Third, there is the inability of organization to retain and develop its human capital resulting in high turnover and a lack of continuity in organizational behavior (Rothwell, 2005). When this occurs, there is a gradual loss of awareness of reality causing dissonance between organizational vision and behavior (O'Neil, 1993). At some point, however, world events or industry changes affect the organization and the gaps in its design and systems shed light on the real state of the organization and its innovative capacity. This reality may be that they are experiencing progressive slow death (Quinn, 1996) and sometimes even organizational failure.

Failure or even the onset of slow death, however, is not and does not have to be inevitable. Within the discovery of organizational pitfalls, there are opportunities to begin to introduce renewal methods to realign organizational design. Sometimes it is in the midst of organizational crisis and chaos that true change can take place (Sanders, 1998). Additionally, within the reality of failure, there is opportunity to reinvent. This in and of itself can generate immense creativity (Sanders, 1998). Reinvention provides opportunity to alter perspective toward a cohesive, synergistic organizational design. In this, there is also the opportunity to infuse renewal practices utilizing self-awareness and self-reflection to reinvent and reinvigorate the organization. This includes not only a renewal of values, but also structures, policies and programs. This is essential, as values not individual leadership philosophies should be the stronger influencer of organizational culture and leadership selection (Mintzberg, Ahlstrand, \& Lampe, 2005). Though organizational renewal requires intentional effort, the future payoffs are worth it. Even more, it is essential for organizational survival and sustainability.

Organizations are multi -dimensional. Furthermore, as the organization progresses through its life cycle, there are opportunities to connect the various dimensions together to work with synergy toward a preferred future. The very essence of organizational design is to create an intelligent organization (Liang, 2002) that utilizes people, values, behaviors, policies, leadership, structures, innovation, and strategy to gain continued organizational momentum. Additionally, within this framework, leadership and organizational renewal does not just take place at moments of crisis, but also in moments of success. The byproduct is a cohesive development and retention of organizational members invested in the future (McDonald, 2008). This is why it is important to consistently reflect, understand, and align all aspects of the organization as part of the ongoing renewal process.

To set the groundwork for organizational renewal, there are three overarching concepts that need defining to provide the framework for the renewal process. These concepts include the basic understanding of the organizational life cycle, a clear definition of self- reflection, and the principle of self-awareness. Once defined, there are two aspects of the organization requiring attention. The first is an assessment of the foundational aspects of the organization itself that includes the very design, value, and people within the organization. The second is an assessment of the structures and processes that become the expressions of the organizational philosophy. 


\subsection{Organization Life Cycle}

Just as there is a human life cycle, so there is also a life cycle within organizations. Though there are varying views as to how many stages of life an organization has, there is consensus that there is a beginning, middle and end (Lester \& Parnell, 2008; Phelps et al., 2007). Some models compare organizational life with that of human life to provide a more organic approach to the organization (Finzell, 1994). This can be helpful in visualizing milestones that occur starting from birth to the completion of life. Within each life stage, the organization is defining and establishing identity (Scott \& Lane, 2000), gauging their competitive advantage within their industry, and establishing organizational structures that reflect their developing identity.

As organizations move within each stage of the life cycle and there is a maturing infrastructure, the natural outcome will be a shift in priorities that affect communication flow, leadership decisions and strategic decisions (Finzell, 1994; Smith et al.). Often what drive these shifts in priorities are the perceived immediate needs of the new phase of the organization (Finzell, 1994; Smith et al.). It is important to note, though needs change and it is appropriate to adjust with the changes, there are strategic moments within each phase where the decisions made raise the long-term stakes for the organization. Additionally, as the organization reaches its maturity or perceived peak of performance, if key decisions and priorities do not promote a long-term innovation renewal perspective there is a potential for the organization to begin to stagnate and lose its competitive advantage.

It is vital that organizations consider their reactions to success within each life cycle phase to remain ahead of the innovation curve. Unfortunately, many organizations begin to plateau loosening their grip and slowing down their innovative process. As this occurs, the established norms and practices begin to drive organizational decision-making (Smith et al., 1985). Though there should be a level of organizational norms and practices that affect the overall movement, there is danger in utilizing those norms and practices to maintain success. If organizations use these norms and practices as a form of cruise control (O'Neil, 1993), then the proven process influences decision making rather than innovative improvement causing the organization to experience innovative decline. This is preventable if, in each life phase, leaders pay attention to the opportunities to contribute to key strategic decisions or tipping points (Phelps et. al, 2007) that determine the resiliency of the organization. These tipping points exist not only on the organizational level, but also on the individual level as leaders and stakeholders contribute to the overall strategic direction of the institution.

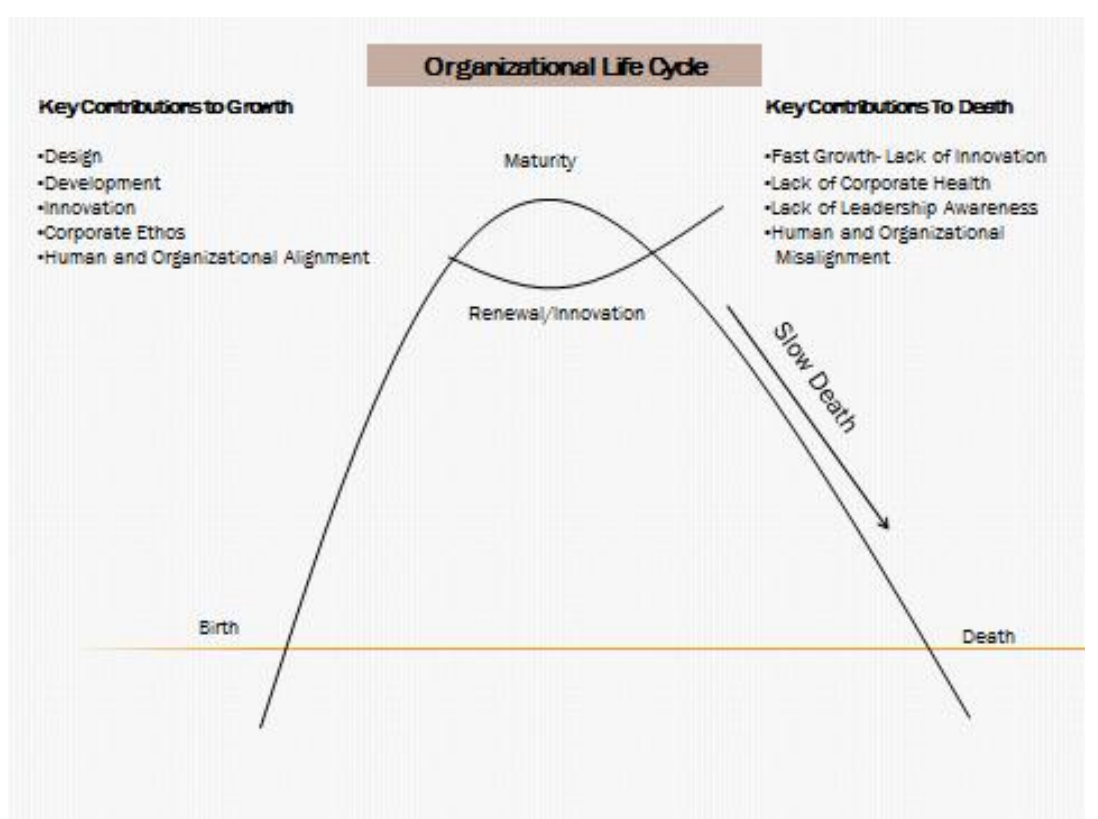

* Image of Curve Adapted From the Following: S-Curve, Paradigm Curve, Barker (1992) and Mapping the Future Gary (2008)

Important to the discussion of organizational effectiveness and renewal is realizing that design, structures, policies, and established norms are not created merely to provide demonstration that the organization exists (Sargent \& 
McConnell, 2008). If that is the view of those seeking to form an organization, than the long- range view of organizational effectiveness is limited. Organizations consist of people. Behaviors and attitudes significantly contribute toward organizational efficacy (Nikolenko \& Kleiner 1996; Beckman, 2009). People and relationships are what produce and generate innovative momentum. For this reason, the discussion of decision-making within each life cycle phase extends to the establishment of behavior that will demonstrate to employees and clients the essence of those who found it. In essence, the decisions made as the organization is maturing drive the basis in which relationships will form. In this case, organizations finding themselves on the road toward organizational death must assess how much is due to a lack of investment in the very fabric of relationship foundation in the formative stages of the organization. This includes realizing the decline of relationship (Quinn, 1996), personal leadership renewal (O'Neil, 1993), and lack of commitment (Whittington \& Galpan, 2010; Quinn, 1996). In regard to relationship establishment, organizations must consider the original systems and structures that determined the way in which relationships were to be formed. Much of what these formative systems and structures include organizational values, leadership style, followership fit, use the enablement of knowledge creation, strategic planning, thinking, and foresight and global competency, and leadership sustainability.

Some scenarios may be beyond the control of the organization (Lester \& Parnell, 2008). However, the ability to reflect and become more aware of what is leading the organization as it proceeds through varying stages within the life cycle can provide key opportunities to self- correct and become more resilient and even possibly find renewal (Lester \& Parnell, 2008) rather than organizational death. Ultimately, how the organization views the life cycle and the continual integration of renewal within each phase will set the path toward organizational effectiveness. Given this, a model for renewal utilizes both self-reflection and self-awareness as a method of discovering the gaps in alignment between both people and systems.

\section{Utilizing Self-Reflection and Self-Awareness for Organizational Renewal}

Organizational renewal requires analyzing both personal leadership and organizational leadership. Additionally, in order for the organization to thrive, both levels need to engage in the renewal process. Renewal literature highlights concepts of self-reflection and self-awareness as a key component to self-efficacy (Cervone, 2008). Another way to refer to self-efficacy is the idea of wholeness in which varying aspects contribute to collective health (Cervone, 2008). From an organizational standpoint, this includes individual as well as organizational capacity for selfreflection and awareness. This capacity is what drives organizational behavior. As capacity increases in the area of self- reflection and self- awareness increases, there is a greater ability to alter behavior (Cervone, 2008).

\subsection{Self- Awareness}

In this context, self-reflection is a conscious movement on both the individual level and organizational level toward a deeper understanding of where the organization is, who they are, from where they have come, and where they are going (Gay \& Kirkland 2003). It is essential that the individual is a part of this process as the social constructs within the organization are what contribute to overall organizational efficacy. A key to self-reflection is the ability to utilize relational intelligence (Pless \& Maak, 2005). Relational intelligence operates on the premises that in order to engage, understand, and make wise decisions two levels of reflection are required. The first level is self-reflection in which one analyzes their own behavioral influences on organizational life (Pless \& Maak, 2005). Important to this process is an authentic look at self, concerning values and decision-making. This moral awareness explores the inner core of what determines personal behavior and ethic. When there is time directed toward recognizing and developing selfreflection capacity, transformation and renewal can emerge (England, 2002). The second level of relational intelligence is being others-reflective. Once there is greater self- clarity, there is a greater ability to see the whole of the organization more clearly. Ultimately, this contributes to recognizing not only personal capabilities and limitations, but also organizational capacity (Cervone, 2008).

\subsection{Self-Reflection}

As one begins to self-reflect, opportunities emerge for greater self-awareness. There is significance in choosing to be cognizant of the personal behavior and values on the overall health of the organization. If an individual chooses to avoid or neglect parts of their behavior that need attention, the more individuals will seek to cover up or disguise the motives behind those behaviors. This creates a dissonance between the private life of the individual and the behaviors demonstrated within the organization (Guinness, 2000). This lack of awareness creates a strain on personal and professional vision and can have lasting effects on both the work environment (Kanji \& Chopra, 2009) and on relationships (Strongman \& Burt, 2000). For this reason, leaders cannot afford to be a stranger to themselves (Dixon, 2009). The more in tune the leader is within himself/herself recognizing their value system, behaviors, surroundings, and pressure points (O’Neil, 1993), the greater capacity the leader has to recognize behaviors on the organizational 
level. In other words, as the scope of awareness expands, the larger picture and personal/organizational capacity become more clear and focused. Additionally, as leaders practice self-awareness the deeper they can expand and explore the human dynamic within the organization (England, 2002). As the leader begins to recognize some of the human dynamics, they will also be able to recognize and activate potentials in others and engage in personal and organizational change (Quinn, 1996). It is hard to change that which is outside of human awareness (Buchanan, 1997). For this reason, reflection with both oneself and others along with self- awareness becomes essential tools for the leader and the organization. They become the framework for self-efficacy including organizational and leadership renewal.

Within this framework of self-reflection and self-awareness, determining what phase of the life cycle the organization is and determining steps for renewal and change can seem unwieldy. As some organizations are facing innovative decline prompting a need to build a framework that can be sustainable, the organization should consider going back to the basics of organizational design with the lens of reflection and awareness as the method by which the organization begins to re-define, reinvent, and possible re-emerge toward greater competitive advantage. The following sections address the key areas within the organization that reflection and awareness are required for greater capacity. Additionally, within this, there is a strong connection between the leader and their contribution to organizational renewal. The key is to analyze the present state of the organization in light of what comes to the surface because of reflection and awareness. There are two parts to this process. The first is to reflect and seek awareness on key foundational pieces such as organizational values, ethics, design, and leadership/followership. The second includes reflection on and awareness of organizational structures and processes, which include knowledge creation/innovation, strategy, and global impact.

\section{Reflection and Awareness of Organizational Values, Ethics, Design, and People}

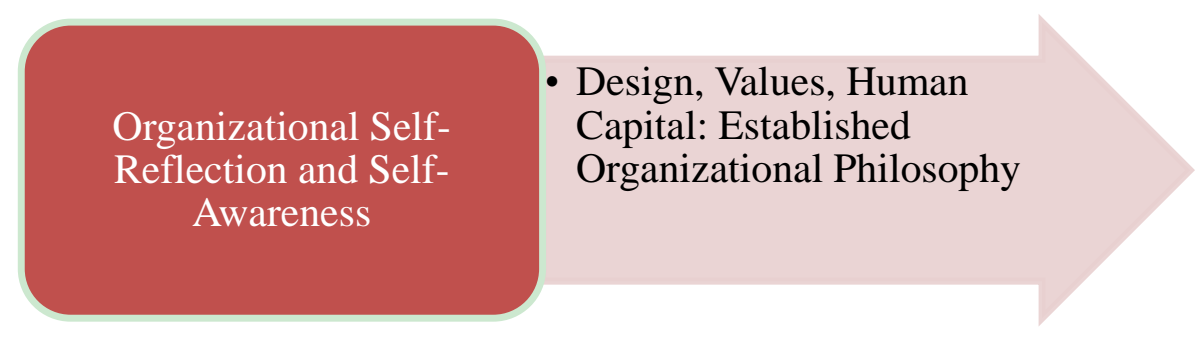

\subsection{Organizational Values}

The establishment and awareness of personal and organizational values provide the foundation and framework by which people interact with each other and the world. Additionally, these values influence the inner structures and policies within an organization creating a standard for ethics and behaviors expected of employees (Cowan \& Todorovic, 2000). A Mission, vision, and core value statements presented by organizations express their identity to all its stakeholders, and becomes the basis of organizational relationship.

Important to this awareness is recognizing where values derive or originate. Some believe values develop in early adolescence or the adolescent stage of the life cycle (O'Grady, 2006, Manno, 1997). Others believe values come out of experiences that lead to the realization of values and its connection to identity (Joas, 2000). Values are sometimes explicit however, some values are not always conscious but rather enfolded in to daily life decisions rarely ever having to be articulated and refined (Hall, 2001). Additionally, values and relationship are intertwined (Hall, 2001,) therefore, as organizations and leaders begin to reflect on current values, there are opportunities to become more aware of the many ways in which values are driving the organization toward effectiveness. Important to recognize are the dynamics involved as varying levels of values are explored. It is easy to identify the surface values that are evident within the organization such as mission statements and standards of conduct (Cowan \& Todorovic, 2000). What are not so easily identifiable are the hidden values, which translate as the long-standing traditions, attitudes, and the deep values that rest in worldview (Cowan \& Todorovic, 2000). Even more important is the depth in which one chooses to explore and align these values as part of the inner richness (England, 2002). This inner richness involves initiating our will to change our values and develop them with self-awareness thus increasing our capacity to emulate effective deep values in relationship to each other. True renewal then occurs when individuals align their personal values with organizational behavior (Hill, 2008). 


\subsection{Ethics}

Furthering the establishment of relationship, ethics becomes the avenue by which the organizations define the identity and behavior of its members. The emulation of values is in the development of ethical standards and practices. As the organization and its leaders reflect and become aware of the root of its value base, the role of ethics within the organization transitions beyond rule following (Wildermuth \& Wildermuth, 2006) or ethical compliance (Tyler et al., 2008) toward a deeper form of desired citizenship behavior (Somech, \& Drach-Zahavy, 2004). In this case, reflecting and becoming aware of a desired inner core allows the organization to evaluate and create a more sustainable ethical framework (Ferguson \& Milliman, 2008) that begins to guide policies and development of social norms (Engelbretcht, 2005). Additionally, there is an intentional aligning of values with the very design of the organization from structures to policies, standard of behavior, and ultimately toward corporate citizenship. This intentional focus on relationship design illuminates the human dynamic and focus needed to sustain organizational effectiveness (Ferguson \& Milliman, 2008). In essence, values and ethics become the way in which employees can become engaged on a relationship level within the organization.

As the organization reflects and creates awareness, there is opportunity to align leaders and followers with the organizational values more adequately (Connor, 2006). This is extremely important to organizational growth as part of sustainability and effectiveness rests in functioning relationships that generate movement and knowledge creation. Alignment affects relationships and the organizational culture. For this reason, an important component to value development is being aware of individual ethical constructs and their ability to integrate ethical principles into their thought processes and daily decisions (Conner, 2006). Additionally, within this process, organizations can begin to take their desired values and reflect on leadership philosophy and followership fit becoming more aware and renewing their alignment within those relationships.

\subsection{Leadership and Followership Approach}

From the foundation of organizational values and ethical constructs of the organization, the discussion of the relationship between leaders and followers provide another piece of the renewal process. It is important to note that there is still a highly leader-centered approach dominating leadership literature (Lord \& Brown, 2003). In the case of organizational sustainability, organizations will be in remiss if they neglect the full capacity and capabilities of those deemed as followers (Frye et al., 2007). Through the self-reflection and awareness process, leaders, followers, and their symbiotic relationship require exploration and development (Gilbert \& Matviuk, 2008). If the premise is that values and organizations are essentially involved in relationship formation and sustainability, reflection is required as to what type of leadership structure is and will remain relevant (Hollander, 1992). In this, both the role of leadership and followership requires exploration. Additionally, reflection is needed as to the symbiotic (Gilbert \& Matviuk, 2008) and shifting states (Stech, 2008) of leaders and followers within the organization.

Leadership identity intertwines with organizational identity (Scott \& Lane, 2000). One can argue that followership identity also intertwines in organizational identity. The organization cannot function solely on the perspective of the leader (Hall \& Densten, 2002). The lens of the follower must also be present. The reflection process provides opportunity for the organization to become more aware of the leadership behavior and impact on organizational culture as well as employees perception of leadership behavior (Tiuraniemi, 2008). This will have an overall effect on organizational effectiveness as both entities establish relationship with one another. If organizations view leadership as a position rather than a process or shifting state, then not only is the leader not operating in their full potential, but neither are followers. In reference to organizational value alignment, both leaders and followers must encompass the same qualities. In fact, both leaders and followers can and do share similar traits that are considered effective in the organization (Lundin \& Lancaster, 1990, Gilbert \& Matviuk, 2008). The role of followership fit should not be underestimated as the mindset of following shapes the dynamics of organizational relationship (Westbrook \& Dixon, 2003) just as much as a formal position or condition of leadership. Each individual leader and follower must recognize how he or she perceives the other (Tiuraniemi, 2008) and establish the foundation of mutuality.

Within leadership renewal, there also needs to be an awareness of what is motivating the leader to lead. There are certain factors that motivate individuals to want to take leadership positions within the organization. Four major factors include personality traits, values, leadership self-efficacy, and previous leadership experiences (Amit, et al., 2007). Each of these four factors involves an intrinsic approach with a deep connection to individual identity. In this case, whatever is motivating the leader to assume leadership responsibilities becomes the lens by which the leader shapes their personal leadership behavior. Leadership style becomes the expression of internal motivation. Additionally, the leadership style or expression chosen will determine decisions and behaviors that directly influence 
follower effectiveness (Winston, 2008). In the context of organizational values, the intrinsic motivator to lead is rooted in personal values (Kark \& Van Dijk, 2007). In other words, chosen leadership style is reflective of a personal value system.

In an organization, the greatest contribution a leader can make is in how they communicate and behave with those they lead. If the leader is not self-aware or reflective about their own motivating factors behind their leadership behaviors, then decisions and key opportunities to contribute toward organizational renewal and sustainability weakens. At times, a lack of self-awareness presents a picture that the leader is victim to the organizational outcomes. In this way, leaders are also operating on cruise control making reactionary decisions without recognizing the connection between personal motivation and style and organizational success. At this point, the discussion of internal motivators and values of the leader does not allude to one leadership style being better or more effective. In the end, whatever motivates personal leadership decisions affects the relationship outcome within the organization (Winston, 2008). As the organization reflects and seeks awareness on the current leadership contribution, it will soon discover whether there is alignment of individual values and the overarching organizational values.

The same can be true for followership. There is power in choosing to follow (Kelley, 1992). More importantly, there are motivators that cause followers to want to follow. Just as leaders have particular leadership styles, followers also have particular needs that lend to a followership style (Kelley, 1992). This in turn affects followership behaviors and decisions as to how they will function within the organization. In this way, followership behavior also affects relationship outcomes (Winston, 2008). For this reason, the relationship formation of leaders and followers with organizational values become the engine for the organization. Processes and structures are then opportunities to express this relationship and value alignment.

\section{Reflection and Awareness of Processes and Structures}

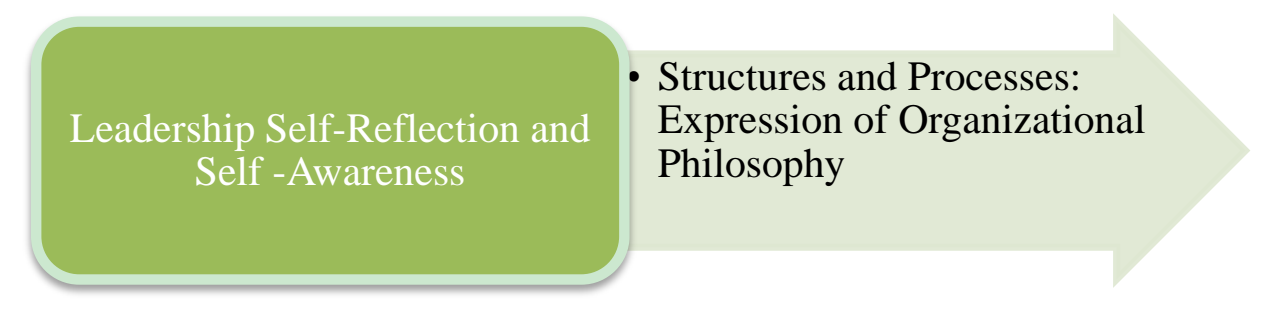

Beginning the renewal process with the human dimensions of the organization provides the foundation to then begin to seek renewal in the actual functioning of internal and external systems. Renewal of processes and structures involves reflecting on and seeking awareness of how to utilize people to their fullest capacity. This includes the process of innovation, strategy, and globalization.

\subsection{Innovation}

As discussed earlier, within the maturing phase of the life cycle, many organizations begin to operate on cruise control allowing for the established successful norms and policies to guide the organization. Unfortunately, one area that begins to decline in importance is innovation. In fact, some researchers believe that it is right before the organization reaches the maturing phase that new innovations must be introduced to maintain momentum and encourage a resurgence of new thought processes to keep the organization from relying on status quo. Even with this perspective, there seems to be a dissonance between a philosophy of innovation and incorporating that philosophy into organizational practices (Cottam, et al., 2001). In this case, innovation emerges at various times within the life cycle or isolated areas within the organization rather than becoming a part of the overall established process within the organization (Cottam, et al., 2001). Within the renewal process, a key area for reflection is in the overarching philosophy or innovation. If innovation is not part of the foundational design, then there is a lack of awareness of how innovation influences not only competitive advantage, but also the human dynamic within the organization (Martins \& Teblanche, 2003). There needs to be an awareness of the impact of individual creativity and organizational innovation (Martins \& Teblanche, 2003). Organizational culture influences whether people participate in innovation (Cottam et al., 2001). Studies have shown that the extent in which a space (Von Krogh, et al., 2000) is created or not created for the process of innovation directly affects innovative behavior, individual creativity, and the overall innovative output of the organization (De Jong \& Hartog, 2007). 
Given this, two key influencers affect the successful operation of innovation within the organization need reflection and awareness. First are the actual structures of the organization (Ahmed, 1998). In the beginning phases of the organization's life, structures and systems establish how people and processes are going to work together. The establishment of innovation practices determines whether the organization will be more organic and fluid encouraging knowledge creation (Ahmed, 1998) or more rigid and constrained attempting to control innovative outcomes.

Second, there needs to be reflection concerning learning behaviors of organizational members (Hirst, et al., 2009). Individual creativity contributes to organizational innovation (Martins \& Teblanche, 2003). Therefore, how employees behave in context of personal and organizational learning affects the collective innovation process (Hirst et al., 2009). Within this context, the key area of awareness is whether the organization and its systems are enabling knowledge creation or seeking to manage innovative outcomes (Von Krogh, et al., 2000). The difference rests in whether the organization facilitates collaboration and diversity of perspective or structure teams to prevent people from operating at full capacity. The more there is an attempt to manage the process of innovation, the greater effect on organizational learning (Von Krogh et al., 2000).

Both structure and people contribute to the innovation process. Within the renewal process organizations need to reflect on and become aware the level of innovative behavior existing in each life cycle phase as well as to begin to integrate innovation within the overarching philosophy. In order to integrate innovation fully, there must be an awareness and reflection on organizational strategy. This includes strategic thinking, planning, and foresight.

\subsection{Organizational Strategy}

There are three dimensions to organizational strategy. The three dimensions include strategic thinking, planning, and foresight. The most common of the three that becomes a default in organizations is strategic planning. Though strategic planning is extremely important to the overall strategic process, it is the last step in the process as it deals with implementation. Unfortunately, many organizations rely simply on strategic planning with no long- term sustainable focus (Hughes \& Beatty, 2005). Within the life cycle phase, all three dimensions of strategy prepare the organization for the future. Additionally, utilizing all three dimensions in the reflection process, can aid the organization in determining future readiness and current challenges that are preventing the organization from fully preparing for sustainable competitive advantage. Strategic thinking in and of itself is the opportunity to reflect on where the organization has been, its present state, and possible future (Graetz, 2002). Strategic thinking provides the framework by which reflection on current systems can generate an understanding of the overall state of the organization concerning change, innovation, and even team efficiency (Graetz, 2002). It also allows employees to make sense of the organizational goals (Bonn, 2005). This is invaluable to organizational renewal, because it is within this framework that the organization can discover if there is synergy between organizational mission/vision with the employee comprehension on how to establish and implement that vision.

Strategic Foresight provides great opportunity for self- reflection and awareness in not only the area of global capacity, but also into the present organizational readiness toward a preferred future. In each phase of the life cycle there are opportunities to utilize strategic foresight to structure and establish innovation as it looks to the horizon. Often this is underutilized because of future phobia (Cornish, 2010) that causes one to only reflect and act on the immediate in denial or with intentional ignorance about the future. This results in a victimization, which blames lack of readiness for the present crisis. This intentional lack of awareness stalls the innovation process and leads the organization toward death. Organizations can be ready for the future and the decisions made today can and will influence the future. Certainly, the future is not predicable, but one can improve upon the future and anticipate the likely conditions of the future (Cornish, 2004). Part of awareness within strategy is to recognize the signposts in the form of trends to see how world trends can affect current organizational readiness. If organizations operate in the status quo at the maturing phase of the organizational life cycle, the rapidly changing world will soon enlighten the organization as it begins to experience decline. Awareness through foresight can help the organization renew itself by seeing the future with some light rather than a black hole. It can become an avenue to be active in the decision making process (Slaughter, 1993).

This is essential to the overall perspective of the organization. The way the organization views and seeks awareness of the future will determine the strategic planning process. There are key elements within foresight that contribute to organizational awareness. These include understanding that 1.) There are long- term consequences for decisions, 2.) Alternative futures imply a use of present choices, 3.) A key to crisis management is forward thinking, and 4.) Radical changes and transformations are a reality as the world shifts and changes (Slaughter, 1993).The past affects understanding of the future, which in turn influences goals and plans for the future (Slaughter, 1993). Though 
foresight models do not seek to predict (Ralston \& Wilson, 2006), it provides awareness and insight into present decision-making giving future possibilities.

When there is greater awareness of the future, then strategic planning becomes the map or guideline to make key decisions that contribute to the organizational strategy (Palmatier \& Wight, 2008). Strategic thinking, planning, and foresight should operate in tandem within each phase of the life cycle. As with innovation, if all three dimensions integrate into the overarching design and culture (Bonn, 2005) of the organization there is a greater opportunity to remain competitive and sustainable while also contributing to organizational renewal.

\subsection{Globalization}

Another important area of focus within organizational strategy is the impact of globalization. As the world is drawing closer together and as some would argue becoming more flat (Friedman, 2005), there is less of a gap between domestic and international business. Within this, the level of global literacy (Rosen et al. 2000) required when forming organizational strategy must be high. Global literacy is not just international competency but an organizational mindset toward how to conduct business in the world. There are distinct differences between the mindset of internationalization and the mindset of globalization (Ruzzier et al., 2006). Whichever view the organization seeks will also determine the scope of its social and cultural realities that are foundational elements to successful globalization. As organizations reflect on whether the strategy encompasses a global mindset, it is important to understand the social and cultural implications surrounding the level of integration into other cultures and markets. This includes whether the current strategy encompasses long- term relationship formation or short -term international integration.

There are two areas where reflection and awareness can illuminate the current organizational mindset. First, organizations must consider their human capital (Odell \& Spielman, 2009). This involves becoming aware of the cultural literacy of organizational members. Second, organizations must consider leadership capacity to operate within a globalized world. This includes being multi-culturally aware and self-aware (Rosen et al., 2000). They must be able to connect and understand their own cultural development (McCall \& Hollenbeck, 2002). Developing a global mindset (Varner \& Palmer, 2005) will require the leader to understand their own culture and orientation first and then develop an understanding of how that affects their communication. Additionally, a global mindset will be contingent on how aware one is with his/her own view of culture and cultural differences (Varner \& Palmer, 2005). This is important to the overall strategic process as the organization seeks to remain competitive in the global market.

Creating a conscious awareness of the interconnectedness of a global mindset and organizational strategy is a huge defense against organizational staleness. As the world is moving quickly and changing constantly, one cannot afford to create separate boxes that isolate each area of the organization from one another. To remain competitive, there needs to be a synergy within all aspects of the organization. The renewal process aids in shaping and strengthening the organizational strategy with relationships and systems.

\section{Bringing Systems and People into Alignment}

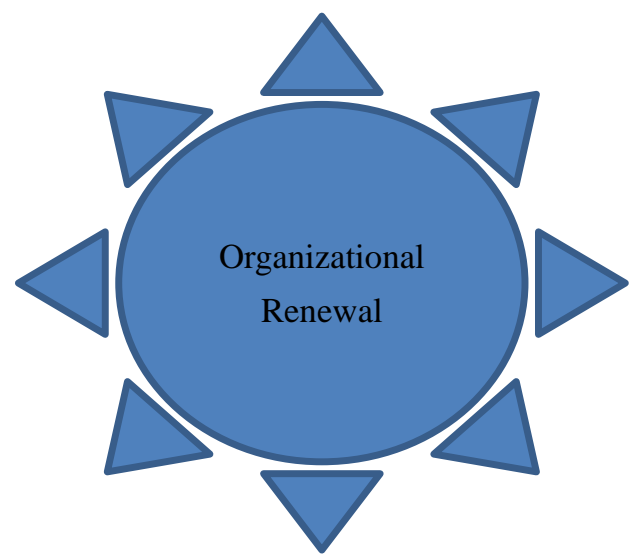

The purpose of renewal in each of these key areas within the organization must be considered intentional. Though some organizations claim to practice renewal it is usually on a micro level with a singular focus (Giachetti, 2009). The result is a collection of isolated decisions and changes that fail to look at the overarching design issues affecting 
strategy, behavior, and relationships (Giachetti, 2009). For this reason, the renewal process links the varying dimensions into a cohesive framework. This provides an opportunity to view people and processes in a more fluid multidimensional way rather than a linear constrained context (Hart, 2008). This includes alignment of organizational values with leadership approach, employee behavior, design and strategy.

Additionally, self-reflection and awareness in each of the areas highlighted allow the opportunity to ensure that the organization is preserved and relevant for the next generation of employees and leaders (Crumpacker \& Crumpacker, 2007). This also illuminates the human capital that exists within the organization and the key processes that contribute to employee effectiveness (Seymour, 2008). The important point is that for renewal to be truly effective, all aspects of the organization must align.

\section{Conclusion}

No matter what phase or shape the organization finds itself, renewal can and should be an integral component. Renewal focusing on self-reflection and self-awareness creates tremendous insight into the various functions and behaviors that contribute to corporate health. In order for there to be effective renewal, organizations must look at the context of both the phase of the organization through understanding the concept of organizational life cycle as well as the key foundations of self-reflection and awareness. Once this is established, the renewal process requires a renewal of core values, approach to people, design, and leadership. In this, there is greater awareness of the foundational behavior elements of the organization. Once there is alignment of values and relationship, the renewal process extends into systems and processes to align the context surrounding organizational behavior.

In the end, a cohesive and intentional reflection and awareness gives the organization the tools to understand the past decision making process of the organization, the present reality and gaps, and the preferred future all within the context of a cohesive framework to initiate change. The work is considerable and engaging the organization in the renewal process must be intentional. The reward however can be a clear and evident alignment that will contribute to future effectiveness and sustainability.

Finally, as practitioners and scholars continue to find methods and solutions for organizational development and change, the importance and interconnectedness of organizational renewal and leadership renewal should not be overlooked. Often, thoughts regarding organizational growth and leadership growth are separated and viewed independently with little intersection in the literature. This empirical study demonstrates the powerful and important thread by which organizations are only as effective as their ability to connect and reflect on both their organizational behavior and leadership behavior. The two are interdependent and this research identifies and articulates the power of their interdependency. Additionally, this empirical study provides a vision organizations can consider as they seek deep transformation for sustainable renewal.

\section{References}

Ahmed, P. (1998). Culture and climate for innovation. European Journal of Innovation Management, 1(1), 30-43. http://dx.doi.org/10.1108/14601069810199131

Amit, K., Lisak, A., Popper, M., \& Gal, R. (2007). Motivation to lead: Research on the motives for undertaking leadership roles in the israel defense forces. Military Psychology, 19(3), 137-160. http://dx.doi.org/10.1080/08995600701386317

Beckman, S. (2009). Introduction to a symposium on organizational design. California Management Review, 51(4), 6-10. http://dx.doi.org/10.2307/41166502

Bonn, I. (2005). Improving strategic thinking: A multilevel approach. Leadership \& Organization Development Journal, 26(5), 336-354. http://dx.doi.org/10.1108/01437730510607844

Buchanan, B. (1997) Assessing human values. Kybernetes, 28(6/7), 703-715. http://dx.doi.org/10.1108/EUM0000000004338

Cervone, D. (2000). Thinking about self-efficacy. Behavior Modification, 24(1), 30-56. http://dx.doi.org/10.1177/0145445500241002

Connor, K. (2006). Assessing organizational ethics: Measuring the gaps. Industrial and Commercial Training, 38(3), 148-155. http://dx.doi.org/10.1108/00197850610659418

Cornish, E. (2004). Futuring: The Exploration of the Future. Bethesda, Maryland; World Futures Society.

Cornish, E. (2010). Foresight conquers fear of the future. The Futurist, 50-51. 
Cottam, A., Ensor, J., \& Band, C. (2001). A benchmark study of strategic commitment to innovation. European Journal of Innovation Management, 4(2), 88-94. http://dx.doi.org/10.1108/14601060110390594

Cowan, C., \& Todorovic, N. (2000). Spiral dynamics. Strategy \& Leadership, 28(1), 4-12. http://dx.doi.org/10.1108/10878570010335912

Crossan, M., \& Berdrow, I. (2015). Organizational learning and strategic renewal. Strategic Management Journal, 24(11), 1087-1105. http://dx.doi.org/10.1002/smj.342

Crumpacker, J. (2007). Succession planning and generational stereotypes: Should hr consider age-based values and attitudes a relevant factor or a passing fad? Public Personnel Management, 36(4), 349-369. http://dx.doi.org/10.1177/009102600703600405

De Jong, J., \& Hartog D. (2007). How leaders influence employees' innovative behavior. European Journal of Innovation, 10(1).

Dixon, D. (2009). Balanced Leaders. LeaderExcel, 19.

Dixon, G., \& Westbrook, J. (2003). Followers revealed. Engineering Management Journal, 15(1), 19-25.http://dx.doi.org/10.1080/10429247.2003.11415192

Engelbrecht, A., Van Aswegen, A., \& Theron, C. (2005). The effect of ethical values on transformational leadership and ethical climate in organizations. South African Journal of Business Management, 36(2), 19-26.

England, D. (2002). Inner leadership-personal transformation. Industrial and Commercial Training, 34(1), 21-27. http://dx.doi.org/10.1108/00197850210414062

Ferguson, J., \& Milliman, J. (2008). Creating effective core organizational values: A spiritual leadership approach. International Journal of Public Administration, 31, 439-459. http://dx.doi.org/10.1080/01900690701590835

Finzell, H. (1994). The Top Ten Mistakes Leaders Make. Colorado Springs, CO: NexGen.

Foster, R. (1998). Streams of Living Water. San Francisco: HarperCollins Publishers.

Friedman, T. (2005). The World is Flat: A Brief History of the Twenty First Century. New York: Farrar, Straus \& Giroux.

Frye, J., Kisselburgh, L. G., \& Butts, D. (2007). Embracing spiritual followership. Communication Studies, 58(3), 243-260. http://dx.doi.org/10.1080/10510970701518355

Gay, G., \& Kirkland, K. (2003). Developing culture critical consciousness and self-reflection in preservice teacher education. Theory into Practice, 42(3), 181-187. http://dx.doi.org/10.1207/s15430421tip4203_3

Giachetti, R. (2009). Design for the Entire Business. Industrial Engineer, 39-43.

Gilbert, J., \& Matviuk, S. (2008). The symbiotic nature of the leader-follower relationship and its impact on organizational effectiveness. Academic Leadership, 6(4).

Graetz, F. (2002). Strategic thinking versus strategic planning: Towards understanding the complementarities. Management Decision, 40(5), 456-462. http://dx.doi.org/10.1108/00251740210430434

Grant, A., Christianson, M., \& Price, R. (2007). Happiness, health, or relationships? managerial practices and employee well-being tradeoffs. Academy of Management Perspectives, 21(3), 51-63. http://dx.doi.org/10.5465/AMP.2007.26421238

Guinness, O. (2000). When No One Sees: The Importance of Character In an Age of Image. Colorado Springs, CO: NavPress.

Hall, B. (2001). Values development and learning organizations. Journal of Knowledge Management, 5(1), 19-32.http://dx.doi.org/10.1108/13673270110384374

Hall, P., \& Densten, I. L. (2002). Following successfully: Followership and technology adoption. Prometheus, 20(2), 87-105.http://dx.doi.org/10.1080/08109020210137484

Hart, S. (2008). Structure that fits for purpose. New Zealand Management, 55(5), 67.

Hill, B. (2008). How learners respond to the teaching of beliefs and values. Journal of Education \& Christian Belief, 12(2), 101-113.http://dx.doi.org/10.1177/205699710801200203

Hirst, G., Knippenberg, D., \& Zhou, J. (2009). A cross-level perspective on employee creativity: Goal orientation, team learning behavior, and individual creativity. Academy of Management Journal, 32(2), 280-293.http://dx.doi.org/10.5465/AMJ.2009.37308035 
Hollander, E.P. (1992). The essential interdependence of leadership and followership. American Psychological Society, Cambridge Press, 71-75. http://dx.doi.org/10.1111/1467-8721.ep11509752

Hughes, R., \& Beatty, K. (2005). Becoming a Strategic Leader. The Center for Creative Leadership, San Francisco: Jossey Bass.

Joas, H. (2000). The Genesis of Values. Chicago: University of Chicago.

Junell, J., \& Stahle, P. (2011). Measuring organizational renewal capability: Case training service business. Competitiveness Review: An International Business Journal, 21(3), 247-268. http://dx.doi.org/10.1108/10595421111134840

Kanji, G., \& Chopra, P. (2009). Psychosocial system for work well-being: On measuring work stress by causal pathway. Total Quality Management \& Business Excellence, 20(5), 563-580. http://dx.doi.org/10.1080/14783360902875741

Kark, R., \& Van Dijk, D. (2007). Motivation to lead, motivation to follow: The role of the self-regulatory focus in leadership processes. Academy of Management Review, 32(2), 500-528. http://dx.doi.org/10.5465/AMR.2007.24351846

Kelley, R. (1992). The Power of Followership: How to Create Leaders People Want to Follow and Followers Who Lead Themselves. New York: Doubleday Currency.

Lester, D., \& Parnell, A. (2008). Firm size and environmental scanning pursuits across organizational life cycle stages. Journal of Small Business and Enterprise Development, 15(3), 540-555. http://dx.doi.org/10.1108/14626000810892337

Liang, T. (2002). The inherent structure and dynamic of intelligent human organizations. Human Systems Management, 21, 9-19.

Lipman-Blumen, J. (Eds.). The art of followership: How great followers create great leaders and organizations, pp. 41-52. San Fransisco: Joessey-Bass.

Lloyd-Jones, M. (1959). Studies in the Sermon on the Mount. Grand Rapids, Michigan: Eerdmans Publishing.

Manno, B. (1975). The identity of jesus and christian discipleship in the gospel of mark. Religious Education, LXX(6), 619-628. http://dx.doi.org/10.1080/0034408750700605

Martins, E., \& Terblanche, F. (2003). Building organizational culture that stimulates creativity and innovation. European Journal of Innovation Management, 6(1), 64-74. http://dx.doi.org/10.1108/14601060310456337

Maslach, C., \& Leiter, M. (1997). The Truth About Burnout: How Organization Cause Personal Stress and What To Do About It. San Francisco: Jossey Bass.

McCall, M., \& Hollenbeck, G. (2002). Developing Global Executives. Boston Massachusetts, Harvard Business School Press.

McDonald, P. (2008). Succession planning as a retention tool. Financial Executive, 24(6), 18-21.

Mintzberg, H., Ahlstrand, B., \& Lampel, J. (2005). Strategy safari: A guided tour through the wilds of strategic management. New York: The Free Press.

Nikolenko, A., \& Kleiner, B. (1996). Global trends in organizational design. Work Study, 45(7), 23-26. http://dx.doi.org/10.1108/00438029610150966

Odell, C., \& Spielman, C. (2009). Global positioning: Managing the far-reaching risks of an international assignment program. Benefits Quarterly, (4), 23-29.

O'Grady, K. (2006). The development of beliefs and values in early adolescence: a case study through religious education pedagogy. International Journal of Children's Spirituality, 11(3), 315-327. http://dx.doi.org/10.1080/13644360601013991

O'Neil, J. (1993). The Paradox of Success. New York, New York, Penguin Group Inc.

Palmatier, G. (2008). Strategic planning: An executive's aid for strategic thinking, development and deployment. Outsourced Logistics.

Phelps, R., Adams, R., \& Bessant, J. (2007). Life cycles of growing organizations: A review with implications for knowledge and learning. International Journal of Management Reviews, 9(1), 1-30. http://dx.doi.org/10.1111/j.1468-2370.2007.00200.x 
Pless, N., \& Maak, T. (2005). Relational Intelligence For Leading Responsibly in a Connected World. Academy of Management Best Conference Paper, 11-16. http://dx.doi.org/10.5465/ambpp.2005.18783524

Pokharel, M., \& Choi, S. (2015). Exploring the relationships between the learning organization and organizational performance. Management Research Review, 38(2), 126-148. http://dx.doi.org/10.1108/MRR-02-2013-0033

Quinn, R. (1996). Deep Change: Discovering The Leaders Within. San Francisco, CA., Jossey-Bass.

Ralston, B., \& Wilson, I. (2006). The Scenario Planning Handbook. Crawfordsville, Indiana, Thomson/South Western.

Riggio R., Challeff I., \& Lipman-Blumen J. (Eds.). The Art of Followership: How Great Followers Create Great Leaders and Organizations, pp. 41-52. San Fransisco: Joessey-Bass.

Rosen, R., Digh, P., Singer, M., \& Phillips, C. (2000). Global Literacies. New York: Simon \& Schuster.

Rothwell, W. (2005). Effective Succession Planning 3rd Edition: Ensuring Leadership Continuity and Building Talent from Within. New York: AMACOM.

Ruzzier, M., Hisrich, R., \& Antoncic, B. (2006). SME internationalization research: Past, present, and future. Journal of Small Business and Enterprise Development, 13(4), 476-49. http://dx.doi.org/10.1108/14626000610705705

Sanders, I. (1998). Strategic Thinking and the New Science. New York: The Free Press.

Sargent, A., \& McConnell, T. (2008). Practical approaches to organization design. CMA Management, 22-25.

Scott, S., \& Lane, V. (2000). A stakeholder approach to organizational identity. Academy of Management Review, 25(1), 43-62. http://dx.doi.org/10.5465/AMR.2000.2791602

Seymour, S. (2008). Boost your business value with succession planning. Management Services, 52(1), 37-39. http://dx.doi.org/10.1108/09670730810878385

Slaughter, R. (1993). Futures concepts. Futures, 289-314. http://dx.doi.org/10.1016/0016-3287(93)90138-J

Smith, K., Mitchell, T., \& Summer, C. (1985). Top level management priorities in different stages of the organizational life cycle. Academy of Management Journal, 28(4), 799-820. http://dx.doi.org/10.2307/256238

Somech, A., \& Drach-Zahavy, A. (2004). Exploring citizenship behavior from an organizational perspective: The relationship between organizational learning and organizational citizenship behavior. Journal of Occupational and Organizational Psychology, 77(3), 281-298. http://dx.doi.org/10.1348/0963179041752709

Stech, E. (2008). A new leadership-followership paradigm. The Art of Followership: How Great Followers Create Great Leaders and Organizations. San Fransisco: Joessey-Bass.

Strongman, K., \& Burt, C. (2000). Taking breaks from work: An exploratory inquiry. Journal of Psychology, 134(3), 229-243. http://dx.doi.org/10.1080/00223980009600864

Tiuraniemi, J. (2008). Leaders self-awareness and its relationship to subordinate assessment of organizational atmosphere in the social welfare sector. Administration in Social Work, 32(4), 23-38. http://dx.doi.org/10.1080/03643100802293824

Tyler, T., Dienhart, J., \& Thomas, T. (2008). The ethical commitment to compliance: Building value-based cultures. California Management Review, 50(2), 19-21. http://dx.doi.org/10.2307/41166434

Varner, I., \& Palmer T. (2005). Role of cultural self-knowledge in successful expatriation. Singapore Management Review, 27(1), 1-25.

Von Korgh, G., Ichijo, K., \& Nonaka, I. (2000). Enabling Knowledge Creation. New York: Oxford University Press. http://dx.doi.org/10.1093/acprof:oso/9780195126167.001.0001

Whittington, J., \& Galpin, T. (2010). The engagement factor: building a high commitment organization in a low commitment world. Journal of Business Strategy, 31(5), 14-24. http://dx.doi.org/10.1108/02756661011076282

Wildermuth, C., \& Wildermuth, M. (2006). Beyond rule following: Decoding leadership ethics. Industrial and Commercial Training, 38(6), 297-301. http://dx.doi.org/10.1108/00197850610685815

Wind, Y. (2006). Blurring the lines: Is there a need to rethink industrial marketing? Journal of Business \& Industrial Marketing, 21(7), 474-481. http://dx.doi.org/10.1108/08858620610708975

Winston, B. E. (2008). Leadership style as an outcome of motive: A contingency 'state' rather than 'trait' Concept. Regent University, 1-11.

Wren, D. (2005). The history of management thought. New York: John Wiley \& Sons. 